\title{
Fetoscopic endoluminal tracheal occlusion and reestablishment of fetal airways for congenital diaphragmatic hernia
}

\author{
Lennart Van der Veeken ${ }^{1}$, Francesca Maria Russo ${ }^{1}$, Luc De Catte ${ }^{1}$, Eduard Gratacos ${ }^{2,3}$, Alexandra Benachi ${ }^{2,4,14}$, \\ Yves Ville ${ }^{2,5}$, Kypros Nicolaides ${ }^{2,6}$, Christoph Berg ${ }^{2,7,8}$, Glenn Gardener ${ }^{2,9}$, Nicola Persico ${ }^{2,10}$, Pietro Bagolan 2,11,14, \\ Greg Ryan ${ }^{2,12}$, Michael A. Belfort ${ }^{2,13}$ and Jan Deprest ${ }^{1,2,14^{*}}$ (i)
}

\begin{abstract}
Background: Congenital diaphragmatic hernia $(\mathrm{CDH})$ is a congenital anomaly with high mortality and morbidity mainly due to pulmonary hypoplasia and hypertension. Temporary fetal tracheal occlusion to promote prenatal lung growth may improve survival. Entrapment of lung fluid stretches the airways, leading to lung growth.

Methods: Fetal endoluminal tracheal occlusion (FETO) is performed by percutaneous sono-endoscopic insertion of a balloon developed for interventional radiology. Reversal of the occlusion to induce lung maturation can be performed by fetoscopy, transabdominal puncture, tracheoscopy, or by postnatal removal if all else fails.

Results: FETO and balloon removal have been shown safe in experienced hands. This paper deals with the technical aspects of balloon insertion and removal. While FETO is invasive, it has minimal maternal risks yet can cause preterm birth potentially offsetting its beneficial effects.

Conclusion: For left-sided severe and moderate $\mathrm{CDH}$, the procedure is considered investigational and is currently being evaluated in a global randomized clinical trial (https://www.totaltrial.eu/). The procedure can be clinically offered to fetuses with severe right-sided $\mathrm{CDH}$.
\end{abstract}

Keywords: FETO, Fetal endoluminal tracheal occlusion, $\mathrm{CDH}$, Congenital diaphragmatic hernia, Fetal surgery, Fetoscopy

\section{Background}

Congenital diaphragmatic hernia $(\mathrm{CDH})$ is a lifethreatening condition affecting up to 3 in 10,000 live born babies [1]. The diaphragmatic defect allows abdominal organs to herniate into the thorax which prevents normal lung development. Depending on the side and size of the defect, this may be the liver, bowel, spleen, and/or stomach. The majority of defects are left sided (LCDH 85\%). Thirteen percent are right sided (RCDH), and bilateral defects or other forms occur very rarely.

\footnotetext{
* Correspondence: jan.deprest@uzleuven.be

${ }^{1}$ Academic Department of Development and Regeneration, Woman and Child, Biomedical Sciences, and Clinical Department of Obstetrics and Gynaecology, KU Leuven, Herestraat 49, 3000, Leuven, Belgium

${ }^{2}$ TOTAL (Tracheal Occlusion To Accelerate Lung Growth Trial) Consortium,

Leuven, Belgium

Full list of author information is available at the end of the article
}

Associated anomalies are frequent and should be ruled out by imaging and genetic testing as they independently influence survival and morbidity. In most registries currently, survival is approximately $70 \%$ depending on the case mix and location of treatment [2]. Surviving patients may suffer from not only medium and long-term morbidity predominantly respiratory in nature, but also gastro-esophageal reflux, failure to thrive, and less common orthopedic or other problems.

Individualized prognosis of isolated $\mathrm{CDH}$ can be made prenatally by using the lung size, the presence of the liver in the thorax, and the side of the defect [3]. Patients with predicted poor prognosis can be offered experimental fetal therapy. To improve survival, the intervention should reverse pulmonary hypoplasia (i.e., stimulate lung growth) before birth. Historically, this 
was attempted by anatomical repair of the defect in utero. The results of this approach were suboptimal [4]. Also, the anatomic defect itself can be relatively easily managed after birth hence it is not the problem. An alternative strategy, based on the clinical observation that fetuses with laryngeal atresia have larger lungs, led to animal experiments that demonstrated that fetal tracheal occlusion reverses experimental pulmonary hypoplasia [5]. Tracheal occlusion leads to accumulation of lung fluid which in turn causes lung stretch. This activates a pathway that leads to proliferation and increased growth of the airways and pulmonary vessels, nicely summarized in the acronym PLUG: "Plug the Lung Until it Grows" (PLUG) [6]. However, when the occlusion is maintained until birth, the number of type II pneumocytes is abnormally low, leading to a relative surfactant deficiency [7]. By reversing the tracheal occlusion before birth, the balance between type I and type II pneumocytes at birth is more optimal. This is captured in the concept "plug-unplug sequence," and reversal of occlusion is an important component in the fetal treatment strategy [7]. Nowadays, tracheal occlusion is uniquely performed by minimally invasive fetal endoluminal tracheal occlusion (FETO) and performed under sonoendoscopic guidance. This is a percutaneous procedure in which a latex balloon is endoscopically positioned above the carina and inflated to occlude the trachea [8] (Fig. 1). The present paper describes the instrumentation and the technical aspects of the FETO procedure as currently performed by the above clinical research consortium within their clinical trial.

\section{Methods \\ Selection of fetuses}

$\mathrm{CDH}$ is typically diagnosed during mid-gestation on screening ultrasound. Following the diagnosis (or suspicion thereof), patients are best referred to a tertiary center where this condition is routinely managed after birth. Patients will be reassessed with targeted ultrasound and magnetic resonance imaging (MRI) and will be offered genetic testing (today this is by micro-array analysis) [9]. This has two purposes, (1) to rule out associated structural or genetic anomalies, which themselves may worsen the prognosis dramatically and (2) to assess the severity of the pulmonary hypoplasia. This information is used to make a personalized prognosis and lead multidisciplinary counseling. Additional evaluation frequently reveals some elements of discordance with the initial assessment at the referring site and may well result in a changed perspective and different parental decisions [10]. Therefore, it is considered prudent to limit prognostic advice at first diagnosis.

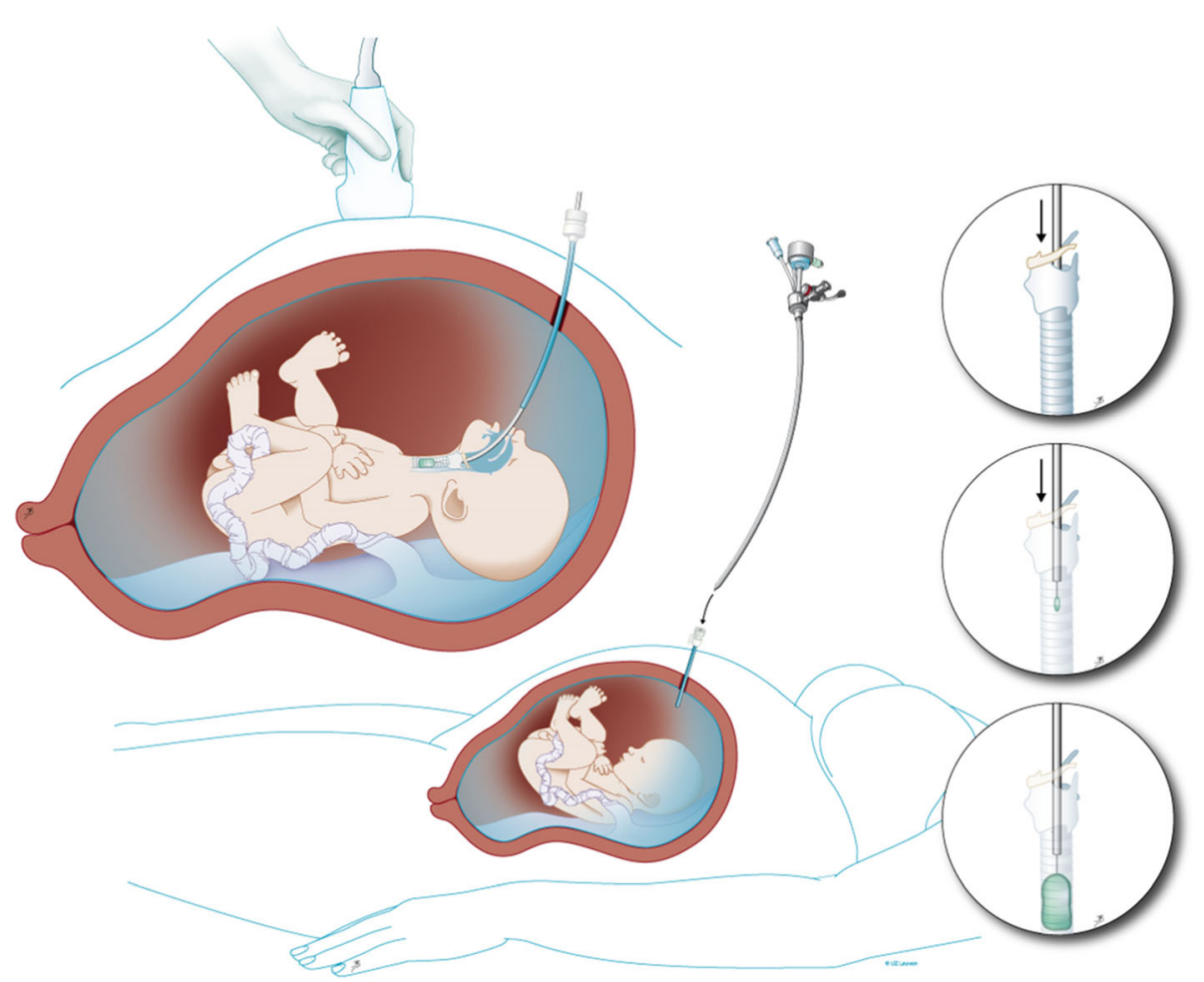

Fig. 1 Fetal endoscopic tracheal occlusion (FETO): a schematic drawing showing access to uterus and the fetal trachea. Inserts: steps in balloon delivery. @ UZ Leuven, UZ Leuven, Belgium, drawing Myrthe Boymans 
In isolated cases, personalized prediction of outcome is based on measurements of lung size, liver position, and the side of the defect [11]. Although other characteristics are being investigated among which stomach position, pulmonary circulatory parameters, and cardiac ventricular size as additional prognostic indicators, the lung-to-head-ratio (LHR) remains the best studied parameter for prediction. The lung contralateral to the lesion is measured in the standard plane for a fourchamber view of the heart, and the head circumference is measured in a standard biparietal view (Fig. 2a, b) [12]. The most accurate way of measuring the lung is by tracing its outline [13]. The LHR measured in the index case (observed) is expressed as a percentage (o/e LHR; $\%)$ of what one would expect in a normal fetus at a similar gestational age (expected). MRI is now almost ubiquitously used in tertiary centers for evaluation of congenital anomalies. In $\mathrm{CDH}$ cases, MRI allows for volumetric measurement of both lungs, the ability to quantitate the degree of liver herniation, and a detailed assessment of stomach position. So far, fetal MRI lung volumetry in $\mathrm{CDH}$ does not provide improved outcome prediction over ultrasound; hence, we do not use it for decisions regarding FETO. The predictive value of imaging methods in terms of pulmonary hypertension or extra-corporeal membrane oxygenation needs is currently under review [14].

Fetuses from singleton pregnancies with a predicted poor postnatal outcome are the target group for fetal intervention. The o/e LHR, presence of the liver in the thorax, and the side of the defect are used so stratify these fetuses [15] (Fig. 2c, d). Babies born beyond 30 weeks with a left-sided $\mathrm{CDH}$, a herniated liver, and an o/e LHR $<25 \%$ who are managed with standard postnatal therapy have a survival rate that is $<20 \%$ [11]. These parameters were therefore used to define that group of fetuses with severe pulmonary hypoplasia, and they formed the initial study population for prenatal therapy. Despite encouraging early experience with FETO [16], fetal surgery for isolated $\mathrm{CDH}$ is still considered experimental. Patients with a fetus who has an isolated LCDH and severe lung hypoplasia are currently being offered participation in a global randomized clinical trial (https://www.totaltrial.eu/) comparing outcomes of FETO to expectant management during pregnancy, followed by standardized postnatal therapy
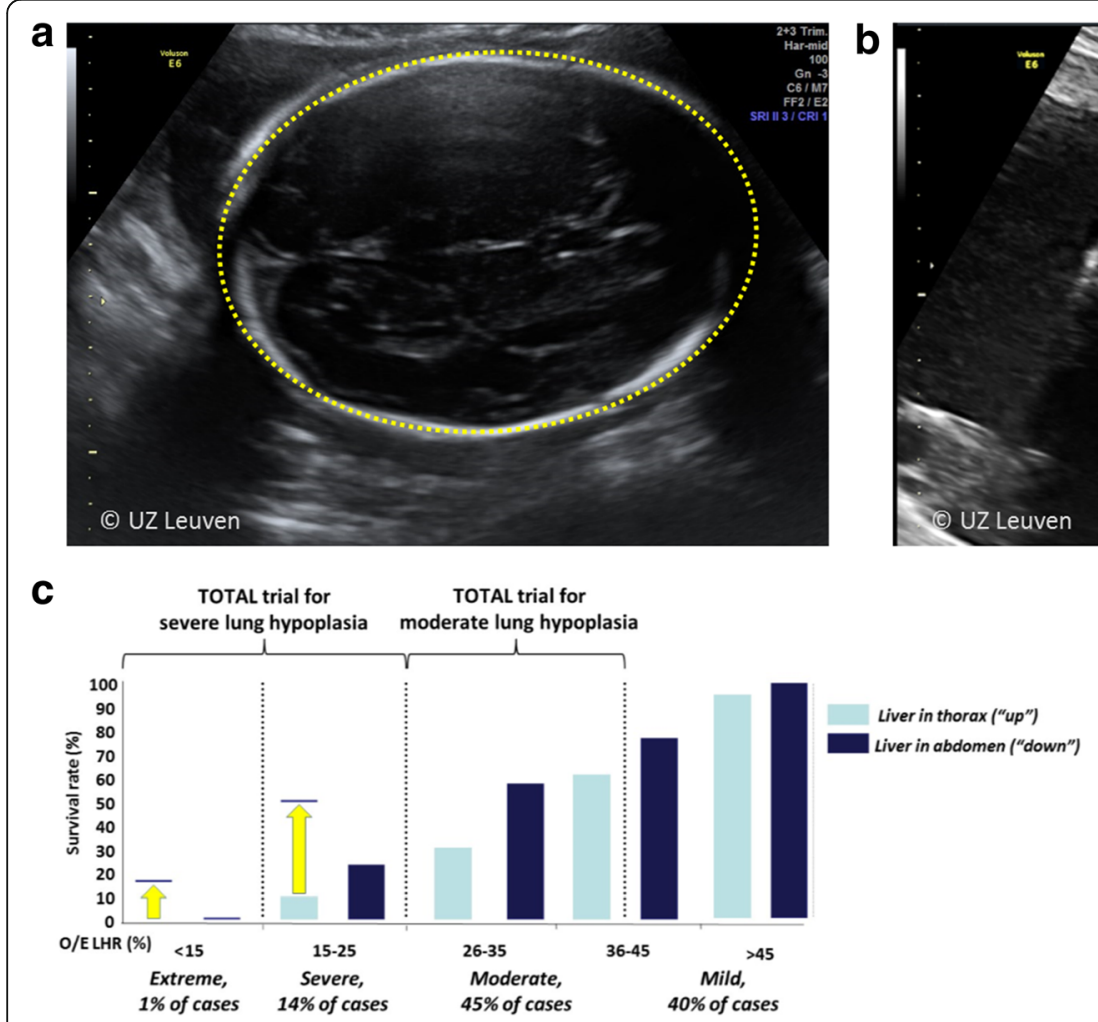

TOTAL trial for

C
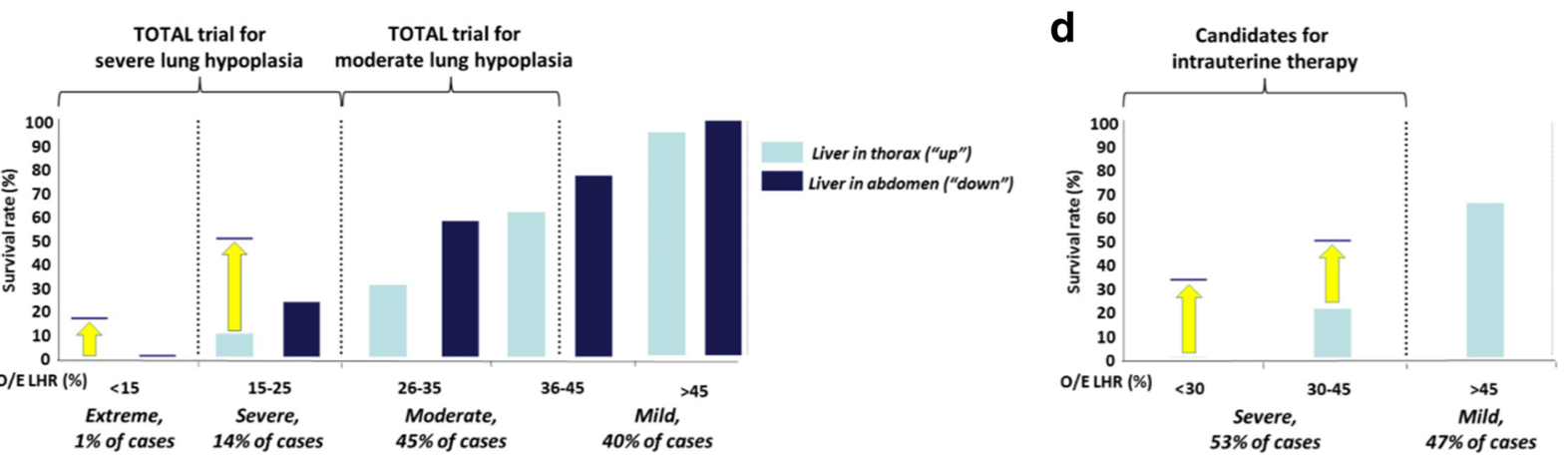

Fig. 2 The o/e LHR is calculated by taking the ratio of the lung area divided by the head circumference, compared to a reference value for that gestational age. a Head circumference. $\mathbf{b}$ Lung area and diameter measured in the plane of the four-chamber view, the lung is posterior to the heart. c Survival rates of fetuses with left-sided CDH expectantly managed during pregnancy, as a function of different o/e LHR and liver position. d Same, for fetuses with right-sided CDH. Yellow arrows indicate improved survival after FETO as reported by Jani et al. 2006 (left CDH) and DeKoninck et al. 2014 (right CDH) [11, 26]. Adapted, with permission, from Russo et al. 2017 [27] 
[17]. In a second experimental arm to this trial, patients with a $\mathrm{CDH}$ fetus with moderate pulmonary hypoplasia (which has a $50 \%$ or greater survival rate) are randomized to FETO or expectant management, in an effort to reduce oxygen dependency at 6 months of age. For $\mathrm{RCDH}$, fetal therapy is offered in case of severe hypoplasia (o/e LHR $<45 \%)$ because they have a predicted survival rate of $17 \%$. For patients who have a more complex presentation with additional findings, a more individualized approach can be taken, yet in the absence of proof of benefit, this is debatable[18, 19].

\section{FETO or PLUG procedure}

FETO was initially performed at 24-28 weeks only in cases of severe $\mathrm{CDH}$ and under epidural anesthesia. Today, the procedure is typically performed under local anesthesia at 27-29 weeks with conscious sedation optional, yet locoregional can be done when clinically required. In moderate cases, FETO is done at $30-32$ weeks. We use prophylactic tocolysis (atosiban or alternatively indomethacin or nifedipine) and antibiotics (cefazolin $2 \mathrm{~g}$ i.v. 8 hourly) until $24 \mathrm{~h}$ after the procedure. The patient is positioned in a dorsal supine position (with lateral tilt to prevent caval compression) such that there is direct access to the fetal mouth. External fetal manipulation may be required. Once in the appropriate position, we administer pancuronium $(0.2 \mathrm{mg} / \mathrm{kg})$ or equivalent, atropine $(20 \mu \mathrm{g} / \mathrm{kg})$, and fentanyl $(15 \mu \mathrm{g} / \mathrm{kg})$ intra-muscularly through a $22 \mathrm{G}$ needle to the fetus to provide analgesia, immobilization, and prophylaxis against bradycardia. After sterile draping, the insertion trajectory is infiltrated with local anesthesia (lidocaine $1 \% 10-20 \mathrm{~mL}$ ). A skin-incision is made and a disposable flexible $10 \mathrm{Fr}$ cannula (3.3 mm; RCF 10.0 Check-Flo Performer, Cook, Bloomington, IN) loaded with a pyramidal trocar (11650TG, Karl
Storz, Tutlingen, Germany) is inserted into the amniotic cavity under ultrasound guidance, in an area devoid of placenta and as perpendicular as possible to the nose tip (Additional file 1: Video S1; Fig. 3). Some introduce the cannula using the Seldinger technique [20].

The fetoscope is a 1.3-mm fiber optic endoscope (11540AA, Karl Storz) housed within a curved 3.3-mm sheath (11540KE; Karl Storz) with a delivery catheter (Baltacci-BDPE-100 $0.9 \mathrm{~mm}$; Balt, Montmorency, France) that is loaded with a detachable inflatable latex balloon with integrated one-way valve (Goldbal2). These are used "offlabel" as they were originally designed for endovascular occlusion. The inflated balloon accommodates for an increasing tracheal diameter during pregnancy. A stylet (11506P; Karl Storz) and grasping forceps (11510C, Karl Storz) are available to puncture and remove the balloon should it be incorrectly positioned (Fig. 4). We flush warmed crystalloid (Hartmann's solution or Ringer's Lactate) through the fetoscope sheath in order to distend the larynx, clear the debris, and improve vision.

Landmarks for balloon insertion are progressively the tip of the nose, philtrum, tongue, the raphe of the palate, uvula, epiglottis, and ultimately the vocal cords (Additional file 2: Video S2; Fig. 5). The fetoscope is advanced into the trachea until the carina is visualized, or if that is not possible, at least to a point where the tracheal rings and pars membranacea can be positively identified. The balloon is then advanced out of the fetoscope, positioned between the cords and the carina, and inflated with $0.6 \mathrm{~mL}$ of isotonic saline. Once inflated, the balloon is detached (Additional file 3: Video S3; Fig. 6a). Finally, excessive amniotic or irrigation fluid is drained until a normal volume is achieved. In our initial experience, the median duration of FETO

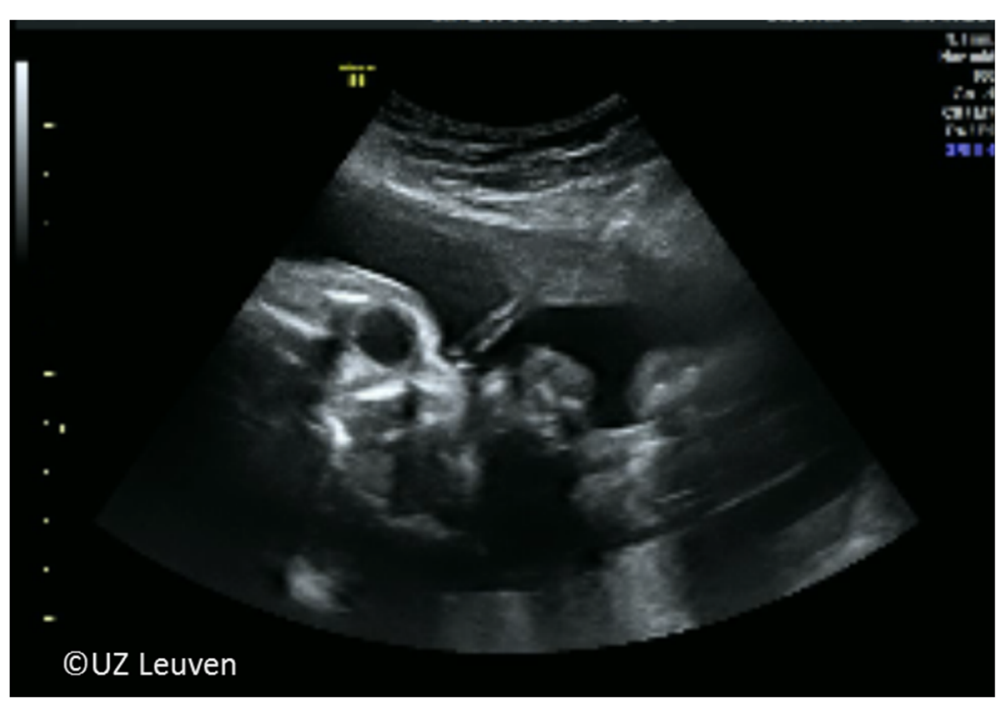

Fig. 3 Transabdominal trocar entry in the direction of the tip of the nose. ๑ UZ Leuven, UZ Leuven, Belgium 


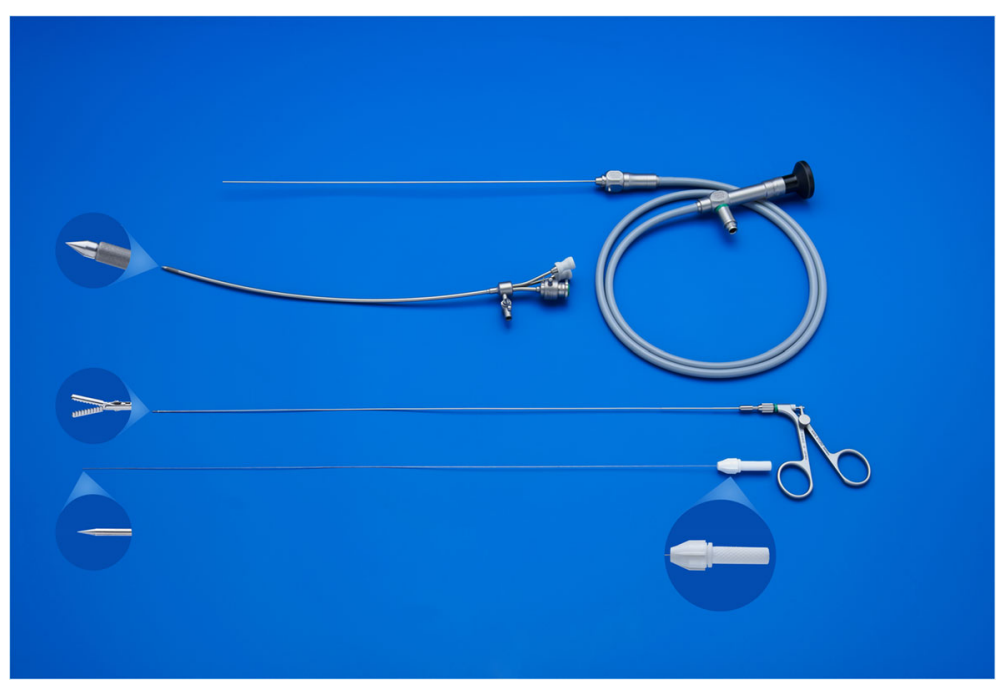

Fig. 4 Fetoscope, fetoscopic forceps, and stylet, courtesy of KARL STORZ Endoskope, Tuttlingen, Germany

was $10 \mathrm{~min}$ (range 3-93 min). Operating time depends mainly on operator experience and on the position of the fetus and is directly related to the risk of chorionic membrane separation and amniorrhexis.

\section{Follow-up}

Patients are followed with ultrasound every 1 to 2 weeks until the preset time for reversal of the occlusion. The fetus is evaluated for growth, movement, general wellbeing and routine antenatal care, and the cervical length is measured to estimate the risk for preterm birth. Amniotic fluid volume is measured to exclude polyhydramnios as this is common in $\mathrm{CDH}$ and can increase the risk of amniorrhexis and/or preterm labor. Amniodrainage is performed when the deepest vertical pool exceeds $12 \mathrm{~cm}$. The membranes are inspected for amnion-chorion membrane separation. At each visit, the balloon is visualized since spontaneous deflation has been described [21]. The tracheal balloon appears on ultrasound as a hypoechoic fluid-filled structure without color Doppler flow and positioned just beneath the vocal cords between the common carotid arteries (Fig. $6 \mathrm{~b})$. Within a week following FETO, the fetal lung in responders becomes hyperechogenic. The parenchymal dimensional changes are quantified via the o/e LHR or MRI. Volume changes precede the vascular response. In case of amniorrhexis or preterm labor, the patients are admitted and management is individually planned for timely and safe balloon removal. Chorioamnionitis is the most common complication of membrane rupture and may mandate balloon removal and delivery. Antepartum hemorrhage has been described yet is in our experience uncommon [21].

\section{UNPLUG or balloon removal}

Our policy is to remove the balloon in utero even if delivery is imminent. It triggers lung maturation, increases survival chances, reduces morbidity [22, 23], and permits

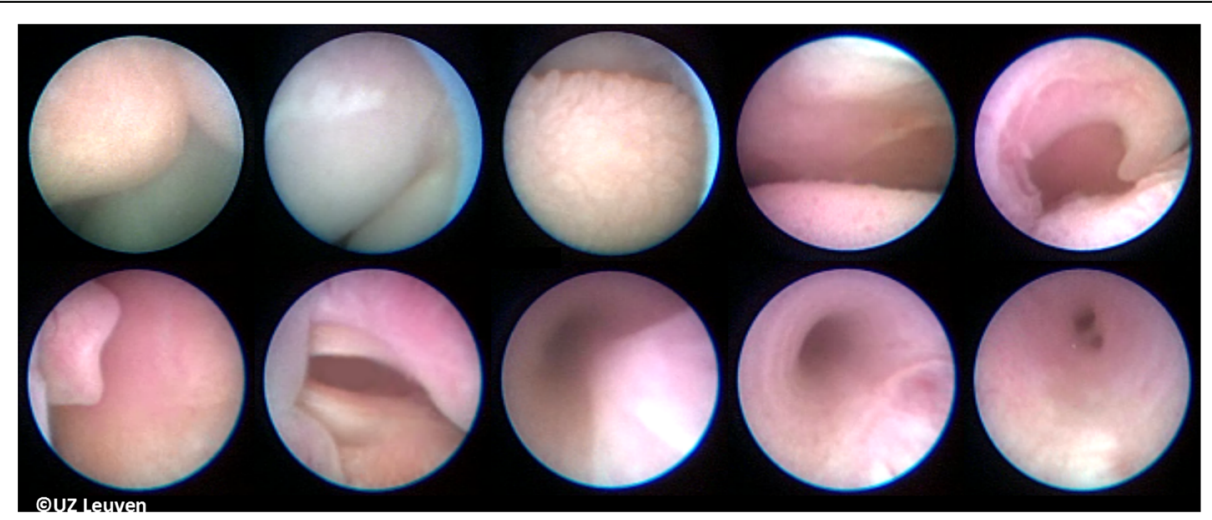

Fig. 5 Landmarks used for guidance from the tip of the nose to trachea. Up from left to right: tip of nose, upper lip, tongue, raphe palate, and uvula. Down from left to right: epiglottis, vocal cords, trachea with inwards bulging pars membranacea, trachea more expanded and also better visualization of the tracheal rings, and carina. ๑ UZ Leuven, UZ Leuven, Belgium 

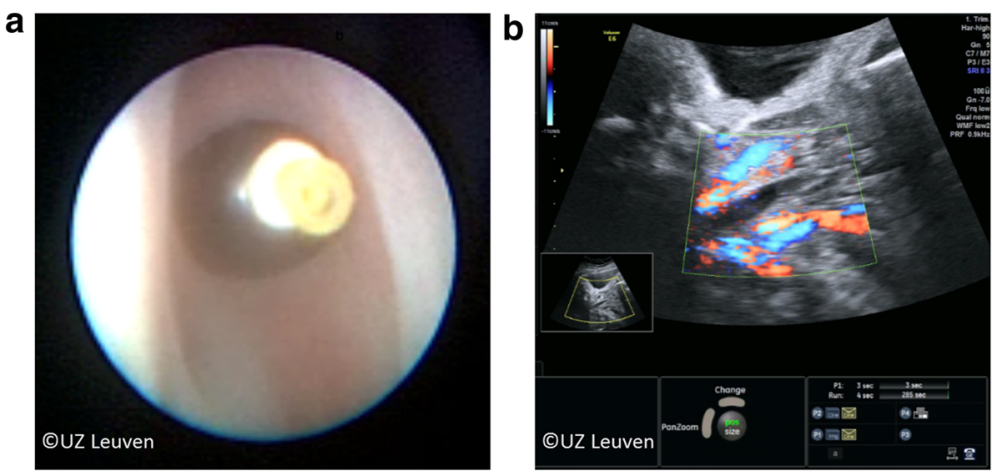

Fig. 6 a After detachment the balloon can be seen through the vocal cords which are in this case just above it. $\mathbf{b}$ On ultrasound the balloon is visible as a hypoechogenic area. Power Doppler can help to distinguish the balloon from the adjacent blood vessels. ๑ UZ Leuven, UZ Leuven, Belgium

vaginal delivery. Removal of the balloon is scheduled at 34 weeks gestational age based on observations in sheep. In $28 \%$ of cases, balloon removal will be indicated earlier because of impending delivery [23]. Steroids are given to enhance lung maturation. The removal takes place in essentially the same preparation as described above for balloon placement, with the same fetal and maternal medications. The balloon can be punctured directly using a 20-22G needle under ultrasound guidance and in our experience is expulsed spontaneously. (Additional file 4: Video S4). In such cases, tracheal patency can be confirmed by demonstration of tracheal fluid movement with Doppler (Additional file 5: Video S5), change in tracheal diameter, or by MRI. The balloon can also be fetoscopically removed, which provides direct visualization of unobstructed airways (Additional file 6: Video S6). In the event that fetoscopic in utero removal is not possible, we resort to tracheoscopic removal (Table 1 for instruments) with the baby on placental circulation under locoregional anesthesia (Fig. 7 and Additional file 7: Video S7). The fetal head and shoulders are delivered and direct laryngo-tracheoscopy is performed. In the worst (and not desirable) scenario, postnatal puncture from above the manubrium sterni is used, with or without ultrasound guidance, or by tracheoscopy. In a report on 302 cases, $67 \%$ of balloon removals were by fetoscopy, $21 \%$ by puncture, and $10 \%$ by tracheoscopy on placental circulation, and $1 \%$ ex utero [23]. In that study, the technique used

Table 1 Overview of the fetoscopic instruments used for FETO and UNPLUG

\begin{tabular}{|c|c|c|}
\hline Fetal tracheoscopy & Description & ID \\
\hline $1.3 \mathrm{~mm}$ endoscope & Miniature telescope, with remote eyepiece $0^{\circ}$ straight forward, $30.6 \mathrm{~cm}$ working length & $11540 \mathrm{AA}$ \\
\hline $3.3 \mathrm{~mm}$ sheath & $\begin{array}{l}\text { Blunt curved sheath, with sand-blasted echogenic tip with stop cock for irrigation and two side } \\
\text { openings }\end{array}$ & 11540KE \\
\hline $1.0 \mathrm{~mm}$ forceps & Retrieval forceps, double action jaws, 35 cm long & $11510 C$ \\
\hline 0.4 mm stylet & Single use puncture stylet with adjustable torque, $50 \mathrm{~cm}$ long & $11506 \mathrm{P}$ \\
\hline $0.9 \mathrm{~mm}$ needle & Puncture needle to protect the catheter or for aspiration, length $35 \mathrm{~cm}$, can house the stylet & $11540 \mathrm{KD}$ \\
\hline $3.3 \mathrm{~mm}$ trocar & 10 Fr pyramidal tipped trocar for use with flexible cannula RCF-10.0 (Cook, Check Flo Performer) & $11650 T G$ \\
\hline $0.6 \mathrm{~mL}$ balloon & $\begin{array}{l}\text { Goldbal } 2 \text { detachable latex balloon with radio-opaque inclusion, outer diameter } 1.5 \mathrm{~mm} \text { (inflated: } \\
7.0 \mathrm{~mm} \text { ); length } 5.0 \mathrm{~mm} \text { (inflated } 20.0 \mathrm{~mm} \text { ) }\end{array}$ & Goldbal 2 (Balt) \\
\hline $0.9 \mathrm{~mm}$ microcatheter & $\begin{array}{l}\text { catheter loaded with mandrel, and Touhy Boost Y-connection, max outer diameter } 0.9 \mathrm{~mm} \text {, tapered } \\
\text { to } 0.4 \mathrm{~mm}, 100 \mathrm{~cm} \text { in length }\end{array}$ & $\begin{array}{l}\text { "Baltacci" e BDPE } \\
100 \text { (Balt) }\end{array}$ \\
\hline $\begin{array}{l}\text { Direct bronchoscopy } \\
1.3 \mathrm{~mm} \text { endoscope }\end{array}$ & Miniature telescope, with remote eyepiece $0^{\circ}$ straight forward, $18.8 \mathrm{~cm}$ working length & 10040AA \\
\hline $\begin{array}{l}\text { Straight bronchoscopic } \\
\text { sheath }\end{array}$ & $\begin{array}{l}4.2 \mathrm{~mm} \text { outer, } 3.5 \mathrm{~mm} \text { inner diameter } 18.5 \mathrm{~cm} \text { length (size } 2.5) \text {, is conventional neonatal "Doesel- } \\
\text { Huzly" bronchoscope, with blanking and suction plug }\end{array}$ & $\begin{array}{l}\text { 10339F } \\
10924 S P \\
10315 R V\end{array}$ \\
\hline Telescope bridge & Houses telescope and has side opening for irrigation $1.5 \mathrm{~mm}$ outer diameter & $10338 \mathrm{LCl}$ \\
\hline $1.0 \mathrm{~mm}$ forceps & $19 \mathrm{~cm}$ semi-flexible forceps for balloon retrieval & $10338 \mathrm{H}$ \\
\hline $0.4 \mathrm{~mm}$ stylet & Single use puncture stylet with adjustable torque, $50 \mathrm{~cm}$ long & $11506 \mathrm{P}$ \\
\hline
\end{tabular}

Endoscopic instruments were developed by Karl Storz Endoskope, supported by the European Commission in the 6th framework program. The balloon system is an adapted version of a commercially available vascular occlusion device. Most instruments and devices are used off label 


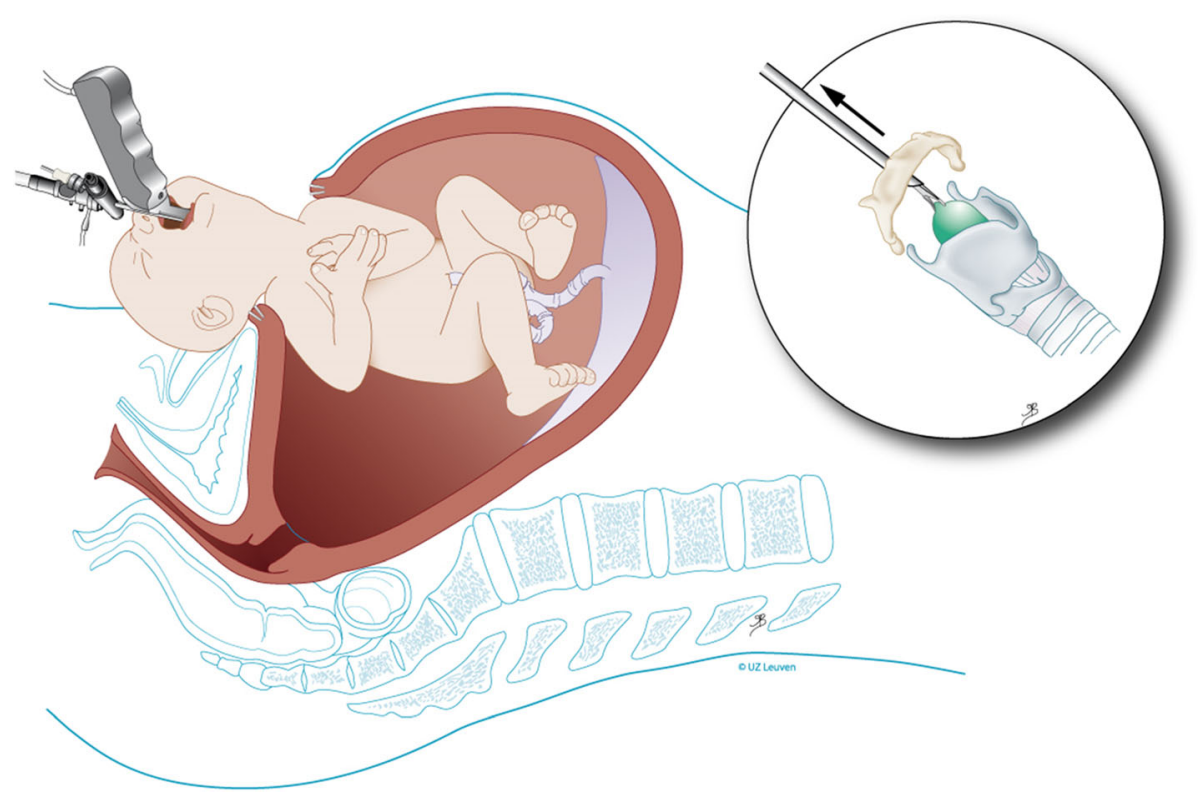

Fig. 7 Schematic drawing of tracheoscopic removal on placental circulation under loco-regional anesthesia. @ UZ Leuven, UZ Leuven, Belgium, drawing Myrthe Boymans

appeared to be dictated mainly by operator preference. There was no difference in gestational age at delivery whether the balloon was punctured or removed by fetoscopy. The importance of immediate availability of trained and experienced operators who can remove a FETO balloon rapidly and safely cannot, and must not, be underestimated. To our knowledge, the only neonatal deaths directly due to balloon removal difficulties that have occurred happened when delivery took place in an unprepared and/or inexperienced environment [23].

Reported adverse events and side effects with FETO are rare. Fetal tracheomegaly is a recognized entity that usually presents as a barking cough on effort and then resolves over time with minimal long-term implications. There are a few neonates who have had significant longterm tracheal issues, and these appear to have been related to traumatic balloon removal or early insertion $<26$ weeks [24]. This is however an aspect that requires more detailed and long-term follow-up. The main maternal-fetal complication is that of chorionic membrane separation and PPROM with resultant preterm birth. Although the median gestational age at birth is 35 weeks, up to one in three patients deliver prior to 34 weeks, potentially offsetting the effect of the fetal intervention.

\section{Results}

To date, the published data are predominantly based on observational trials and small case series [8]. There is one randomized controlled trial $[25,26]$ that showed benefit of FETO; however, in that study all deliveries were by EXIT procedure, there was a case mix of right and left $\mathrm{CDH}$, and the methodology was substantially different to what is currently being practiced in Europe and the USA.

Compared to historical controls of similar severity, FETO increases survival rate from 24 to $49 \%$ in LCDH with o/eLHR $<25 \%$ and from 17 to $42 \%$ in RCDH with o/ eLHR $<45 \%$ [21, 26] (Fig. 2c, d). FETO also seems to reduce early neonatal respiratory morbidity.

\section{Discussion}

This potential benefit is now being investigated in two parallel randomized clinical trials (RCT) "Tracheal Occlusion To Accelerate Lung growth" (https://www.totaltrial. $\mathrm{eu} /$ ), in fetuses with LCDH and either severe or moderate lung hypoplasia (NCT01240057 and NCT00763737). Current fetal treatment centers are in Leuven, Belgium; Paris, France; London, UK; Barcelona, Spain; Milan and Rome, Italy; Bonn, Germany; Toronto, Canada; Brisbane, Australia; and Houston, Texas, USA. These centers have a high volume fetoscopy program, completed a minimum learning curve of 15 FETO procedures, and committed to strict adherence to a prenatal and postnatal management protocol. The trial has recruited at the time of writing over 165 (moderate) and over 50 (severe) patients. Results are expected within the next 2 years at the current recruitment rate (moderate). We anticipate that more centers in the USA and in Japan will be joining the task force which may accelerate recruitment.

\section{Conclusions}

FETO may alter the natural history of congenital diaphragmatic hernia, and early clinical results look promising. It is 
hoped that the ongoing TOTAL trial will result in proof of benefit. FETO is an invasive technique associated with a significantly increased risk for preterm birth which potentially tempers its benefits. The procedure requires specific skills and instrumentation and permanent services and is at present limited to a select group of centers. If proven effective, this procedure is likely to be implemented more widely and appropriate dissemination will require an extensive training program and careful oversight in order to ensure safe implementation.

\section{Additional files}

Additional file 1: Video S1. The trocar is inserted into the amniotic cavity under ultrasound guidance, in an area devoid of placenta and as perpendicular as possible to the nose tip. Copyright: UZ Leuven, Leuven, Belgium. (MP4 $4355 \mathrm{~kb}$ )

Additional file 2: Video S2. The subsequent landmarks are seen as the fetoscope is advanced to the fetal trachea. Chronologically: lower lip, tongue, uvula, soft palate, epiglottis, vocal cords, and tracheal pars membranacea. Copyright: UZ Leuven, Leuven, Belgium. (AVI 4860 kb)

Additional file 3: Video S3. The balloon is inflated with $0.6 \mathrm{~mL}$ of isotonic saline solution and fills the trachea just distal to the cords, following which it is detached. Copyright: UZ Leuven, Leuven, Belgium. (AVI $6806 \mathrm{~kb}$ )

Additional file 4: Video S4. The balloon is punctured under ultrasound guidance using a 20-22 G needle. The needle is inserted as close as possible to the anterior shoulder, which enables to pass the umbilical cord which is lying on the neck. As the balloon is punctured, the trachea can be seen collapsing. Copyright: UZ Leuven, Leuven, Belgium. (MP4 $5472 \mathrm{~kb})$

Additional file 5: Video S5. After puncturing, the balloon tracheal patency can be confirmed by demonstration free tracheal fluid movement with Doppler. Copyright: UZ Leuven, Leuven, Belgium. (MP4 $3849 \mathrm{~kb})$

Additional file 6: Video S6. Fetoscopic unplugging provides direct documentation of free airways. As the lung fluid egresses, the pressure drops and the trachea will slightly collapse. Copyright: UZ Leuven, Leuven, Belgium. (AVI 2303 kb)

Additional file 7: Video S7. If not possible to puncture the balloon ultrasound guided or fetoscopic guided, we can resort to tracheoscopic removal on placental circulation under loco-regional anesthesia. Copyright: UZ Leuven, Leuven, Belgium. (MP4 6707 kb)

\section{Abbreviations \\ $\mathrm{CDH}$ : Congenital diaphragmatic hernia; EXIT: Ex utero intrapartum treatment; FETO : Fetal endoluminal tracheal occlusion; LCDH: Left-sided congenital diaphragmatic hernia; LHR: Lung-to-head-ratio; MRI : Magnetic resonance imaging; o/e LHR: Observed to expected lung-to-head-ratio; PLUG: Plug the Lung Until it Grows; PPROM: Preterm and Prelabor Rupture Of Membranes; RCDH: Right-sided congenital diaphragmatic hernia; RCT : Randomized clinical trial; TOTAL: Tracheal Occlusion To Accelerate Lung growth}

\section{Funding}

JD is partly funded by the Great Ormond Street Hospital Charity Fund. LVDV is supported by the Erasmus+ Programme of the European Commission (2013-0040). FMR is supported by the KU Leuven (C32/17/ 054). Our research is in part supported by an Innovative Engineering for Health award by the Wellcome Trust (WT101957), the Engineering and Physical Sciences Research Council (NS/A000027/1), and the Fetal Health Foundation (USA).

\section{Authors' contributions}

LVDV, FMR, and JDP wrote the initial manuscript. EG, AB, YV, KN, CB, GG, NP, $P B, G R, M A B, J D P$ are members of the FETO task force and were involved in development of the technique, collection of data, and editing of the manuscript. LDC and JDP acquired the images and clips. All authors read and approved the final version of the manuscript.

\section{Authors' information}

LVDV, FMR, LDC, and JD are in the Academic Department of Development and Regeneration, Woman and Child, Biomedical Sciences, and Clinical Department of Obstetrics and Gynaecology, KU Leuven, Leuven, Belgium. $E G, A B, Y V, K N, C B, G G, N P, P B, G R, M A B$, and JD are members of the TOTAL (Tracheal Occlusion To Accelerate Lung Growth Trial) Consortium.

EG is head of the Barcelona Center for Maternale Fetal and Neonatal Medicine (Hospital Clínic and Hospital Sant Joan de Déu), IDIBAPS, University of Barcelona, and Centre for Biomedical Research on Rare Diseases (CIBER-ER), Barcelona, Spain.

$A B$ is head of the Department of Obstetrics, Gynaecology and Reproductive Medicine, Hôpital Antoine-Béclère, University Paris Sud, Clamart, France. $\mathrm{Y}$ is head of the Fetal Medicine Unit, Obstetrics and Fetal Medicine Department, Necker-Enfants Malades Hospital, Université Paris Descartes, Sorbonne Paris Cité, Paris, France.

$\mathrm{KN}$ is head of the Fetal Medicine Center, Harris Birthright Centre, King's College Hospital, London, UK.

CB is head of the Division of Fetal Surgery, Department of Obstetrics and Prenatal Medicine, University of Bonn, and Department of Obstetrics and Gynecology, University of Cologne, Germany.

GG is head of the Mater Health Services, Mater Research UQ, Brisbane, Australia.

NP is in the Department of Obstetrics and Gynecology "L. Mangiagalli," Fondazione IRCCS "Ca' Granda" - Ospedale Maggiore Policlinico, Milan, Italy. PB is head of Neonatal Surgery Unit, Department of Medical and Surgical Neonatology, Bambino Gesù Children's Hospital, IRCCS, Piazza S. Onofrio, 4, 00165, Rome, Italy.

GR is head of the Fetal Medicine Unit, Mt. Sinai Hospital, and University of Toronto, Toronto, Canada.

MAB is head of the Department of Obstetrics and Gynecology, Baylor College of Medicine and Texas Children's Fetal Center, Houston, Texas, USA. $A B, P B$, and JD are members of the European Reference Network on Rare and Inherited Congenital Anomalies "ERNICA."

Ethics approval and consent to participate

Not applicable.

\section{Competing interests}

The authors declare that they have no competing interests.

\section{Publisher's Note}

Springer Nature remains neutral with regard to jurisdictional claims in published maps and institutional affiliations.

\footnotetext{
Author details

${ }^{1}$ Academic Department of Development and Regeneration, Woman and Child, Biomedical Sciences, and Clinical Department of Obstetrics and Gynaecology, KU Leuven, Herestraat 49, 3000, Leuven, Belgium. ${ }^{2}$ TOTAL (Tracheal Occlusion To Accelerate Lung Growth Trial) Consortium, Leuven, Belgium. ${ }^{3}$ BCNatal Barcelona Center for MaternaleFetal and Neonatal Medicine (Hospital Clínic and Hospital Sant Joan de Déu), IDIBAPS, University of Barcelona, and Centre for Biomedical Research on Rare Diseases (CIBER-ER), Barcelona, Spain. ${ }^{4}$ Department of Obstetrics, Gynaecology and Reproductive Medicine, Hôpital Antoine-Béclère, University Paris Sud, Clamart, France. ${ }^{5}$ Fetal Medicine Unit, Obstetrics and Fetal Medicine Department, Necker-Enfants Malades Hospital, Université Paris Descartes, Sorbonne Paris Cité, Paris, France. 'Harris Birthright Centre, King's College Hospital, London, UK. ${ }^{7}$ Division of Fetal Surgery, Department of Obstetrics and Prenatal Medicine, University of Bonn, Bonn, Germany. ${ }^{8}$ Department of Obstetrics and Gynecology, University of Cologne, Cologne, Germany. ${ }^{9}$ Mater Health Services, Mater Research UQ, Brisbane, Australia. ${ }^{10}$ Department of Obstetrics and Gynecology, "L. Mangiagalli," Fondazione IRCCS "Ca' Granda" - Ospedale Maggiore Policlinico, Milan, Italy. " Neonatal Surgery Unit, Department of Medical and Surgical Neonatology, Bambino Gesù Children's Hospital, IRCCS, Piazza S. Onofrio, 4, 00165 Rome, Italy. ${ }^{12}$ Fetal
} 
Medicine Unit, Mt Sinai Hospital, University of Toronto, Toronto, Canada. ${ }^{13}$ Department of Obstetrics and Gynecology, Baylor College of Medicine and Texas Children's Fetal Center, Houston, Texas, USA. ${ }^{14}$ European Reference Network on Rare and Inherited Congenital Anomalies "ERNICA", Rotterdam, The Netherlands.

Received: 15 December 2017 Accepted: 12 April 2018

Published online: 08 May 2018

\section{References}

1. EUROCAT. EUROCAT statistical monitoring report - 2012

2. Harting MT, Lally KP (2014) The congenital diaphragmatic hernia study group registry update. Semin Fetal Neonatal Med 19:370-375

3. Claus F, Sandaite I, Dekoninck P, Moreno O, Cruz Martinez R, Van Mieghem T, Gucciardo L, Richter J, Michielsen K, Decraene J, Devlieger R, Gratacos E, Deprest JA (2011) Prenatal anatomical imaging in fetuses with congenital diaphragmatic hernia. Fetal Diagn Ther 29:88-100

4. Harrison MR, Langer JC, Adzick NS, Golbus MS, Filly RA, Anderson RL, Rosen MA, Callen PW, Goldstein RB, de Lorimier AA (1990) Correction of congenital diaphragmatic hernia in utero, V. Initial clinical experience. J Pediatr Surg 25: 47-55 discussion 56-7

5. Wilson JM, DiFiore JW, Peters CA (1993) Experimental fetal tracheal ligation prevents the pulmonary hypoplasia associated with fetal nephrectomy: possible application for congenital diaphragmatic hernia. J Pediatr Surg 28: 1433-1439 discussion 1439-40

6. Hedrick MH, Estes JM, Sullivan KM, Bealer JF, Kitterman JA, Flake AW, Adzick NS, Harrison MR (1994) Plug the lung until it grows (PLUG): a new method to treat congenital diaphragmatic hernia in utero. J Pediatr Surg 29:612-617

7. Flageole H, Evrard VA, Piedboeuf B, Laberge JM, Lerut TE, Deprest JA (1998) The plug-unplug sequence: an important step to achieve type II pneumocyte maturation in the fetal lamb model. J Pediatr Surg 33:299-303

8. Deprest J, Gratacos E, Nicolaides KH, Group FT (2004) Fetoscopic tracheal occlusion (FETO) for severe congenital diaphragmatic hernia: evolution of a technique and preliminary results. Ultrasound Obstet Gynecol 24:121-126

9. Brady PD, Delle Chiaie B, Christenhusz G, Dierickx K, Van Den Bogaert K, Menten B, Janssens S, Defoort P, Roets E, Sleurs E, Keymolen K, De Catte L, Deprest J, de Ravel T, Van Esch H, Fryns JP, Devriendt K, Vermeesch JR (2014) A prospective study of the clinical utility of prenatal chromosomal microarray analysis in fetuses with ultrasound abnormalities and an exploration of a framework for reporting unclassified variants and risk factors. Genet Med 16:469-476

10. Done E, Gucciardo L, Van Mieghem T, Devriendt K, Allegaert K, Brady P, Devlieger R, De Catte L, Lewi L, Deprest J (2017) Clinically relevant discordances identified after tertiary reassessment of fetuses with isolated congenital diaphragmatic hernia. Prenat Diagn 37:883-888

11. Jani J, Nicolaides KH, Keller RL, Benachi A, Peralta CF, Favre R, Moreno O, Tibboel D, Lipitz S, Eggink A, Vaast P, Allegaert K, Harrison M, Deprest J, Antenatal CDHRG (2007) Observed to expected lung area to head circumference ratio in the prediction of survival in fetuses with isolated diaphragmatic hernia. Ultrasound Obstet Gynecol 30:67-71

12. Deprest JA, Flemmer AW, Gratacos E, Nicolaides K (2009) Antenatal prediction of lung volume and in-utero treatment by fetal endoscopic tracheal occlusion in severe isolated congenital diaphragmatic hernia. Semin Fetal Neonatal Med 14:8-13

13. Jani J, Peralta CF, Benachi A, Deprest J, Nicolaides KH (2007) Assessment of lung area in fetuses with congenital diaphragmatic hernia. Ultrasound Obstet Gynecol 30:72-76

14. Russo FM, Eastwood MP, Keijzer R, Al-Maary J, Toelen J, Mieghem TV, Deprest JA (2016) Lung size and liver herniation predict the need for extra corporeal membrane oxygenation but not pulmonary hypertension in isolated congenital diaphragmatic hernia: a systematic review and metaanalysis. Ultrasound Obstet Gynecol, 2017. 49(6):704-13.

15. Metkus AP, Filly RA, Stringer MD, Harrison MR, Adzick NS (1996) Sonographic predictors of survival in fetal diaphragmatic hernia. J Pediatr Surg 31:148-151 discussion 151-2

16. Al-Maary J, Eastwood MP, Russo FM, Deprest JA, Keijzer R (2016) Fetal tracheal occlusion for severe pulmonary hypoplasia in isolated congenital diaphragmatic hernia: a systematic review and meta-analysis of survival. Ann Surg 264:929-933

17. Deprest J, Brady P, Nicolaides K, Benachi A, Berg C, Vermeesch J, Gardener G, Gratacos E (2014) Prenatal management of the fetus with isolated congenital diaphragmatic hernia in the era of the TOTAL trial. Semin Fetal Neonatal Med 19:338-348

18. Seravalli V, Jelin EB, Miller JL, Tekes A, Vricella L, Baschat AA (2017) Fetoscopic tracheal occlusion for treatment of non-isolated congenital diaphragmatic hernia. Prenat Diagn 37:1046-1049

19. Van Mieghem T, Cruz-Martinez R, Allegaert K, Dekoninck P, Castanon M, Sandaite I, Claus F, Devlieger R, Gratacos E, Deprest J (2012) Outcome of fetuses with congenital diaphragmatic hernia and associated intrafetal fluid effusions managed in the era of fetal surgery. Ultrasound Obstet Gynecol 39:50-55

20. Deprest JA, Van Schoubroeck D, Van Ballaer PP, Flageole H, Van Assche FA, Vandenberghe K (1998) Alternative technique for Nd: YAG laser coagulation in twin-to-twin transfusion syndrome with anterior placenta. Ultrasound Obstet Gynecol 11:347-352

21. Jani JC, Nicolaides KH, Gratacos E, Valencia CM, Done E, Martinez JM, Gucciardo L, Cruz R, Deprest JA (2009) Severe diaphragmatic hernia treated by fetal endoscopic tracheal occlusion. Ultrasound Obstet Gynecol 34:304-310

22. Done E, Gratacos E, Nicolaides KH, Allegaert K, Valencia C, Castanon M, Martinez JM, Jani J, Van Mieghem T, Greenough A, Gomez O, Lewi P, Deprest J (2013) Predictors of neonatal morbidity in fetuses with severe isolated congenital diaphragmatic hernia undergoing fetoscopic tracheal occlusion. Ultrasound Obstet Gynecol 42:77-83

23. Jimenez JA, Eixarch E, DeKoninck P, Bennini JR, Devlieger R, Peralta CF, Gratacos E, Deprest J (2017) Balloon removal after fetoscopic endoluminal tracheal occlusion for congenital diaphragmatic hernia. Am J Obstet Gynecol 217:78 e1-78 e11

24. Deprest J, Breysem L, Gratacos E, Nicolaides K, Claus F, Debeer A, Smet MH, Proesmans M, Fayoux P, Storme L (2010) Tracheal side effects following fetal endoscopic tracheal occlusion for severe congenital diaphragmatic hernia. Pediatr Radiol 40:670-673

25. Ruano R, Yoshisaki CT, da Silva MM, Ceccon ME, Grasi MS, Tannuri U, Zugaib M (2012) A randomized controlled trial of fetal endoscopic tracheal occlusion versus postnatal management of severe isolated congenital diaphragmatic hernia. Ultrasound Obstet Gynecol 39:20-27

26. DeKoninck P, Gomez O, Sandaite I, Richter J, Nawapun K, Eerdekens A, Ramirez JC, Claus F, Gratacos E, Deprest J (2015) Right-sided congenital diaphragmatic hernia in a decade of fetal surgery. BJOG 122:940-946

27. Russo FM, De Coppi P, Allegaert K, Toelen J, van der Veeken L, Attilakos G, Eastwood MP, David AL, Deprest J (2017) Current and future antenatal management of isolated congenital diaphragmatic hernia. Semin Fetal Neonatal Med 22:383-390

\section{Submit your manuscript to a SpringerOpen ${ }^{\circ}$ journal and benefit from:}

- Convenient online submission

- Rigorous peer review

- Open access: articles freely available online

- High visibility within the field

Retaining the copyright to your article

Submit your next manuscript at $>$ springeropen.com 